\title{
Body Shape Dissatisfaction and Overweight Noesis among Polytechnic College students in Puducherry-
} A Cross Sectional Study

\author{
Vishnu Prasad R ${ }^{1}$, Kanimozhy $\mathrm{K}^{1}$, Venkatachalam $\mathrm{J}^{2}$, Madhanraj $\mathrm{K}^{2}$, Zile Singh ${ }^{3}$
}

\section{ABSTRACT}

The prevalence of obesity has doubled since 1980 worldwide. With the changing dietary and life style habits, overweight and obesity have become a threat globally. As on 2011, more than 40 million children worldwide are overweight and more than 30 million of them are living in developing countries. Body image perception of an individual plays a major role in determining the diet and lifestyle modification to alter their body shape.Materials and methods: The study was carried out among 1034 polytechnic college students in Puducherry aged 15-25 years as a cross sectional study. Stunkard's visual figures scale was used to measure Body Shape Dissatisfaction.Statistical analysis: Chi-square test was used to test the statistical significance in difference between proportions, $\mathrm{p}$ value $<0.05$ was considered statistically significant.Results:The prevalence of Body Shape Dissatisfaction in our study subjects was found to be $62.2 \%$. More female students wanted a thinner body shape while more male students wanted a bigger body shape than their current body shape. $45.3 \%$ of the students with normal BMI were satisfied with their current body shape, $26 \%$ of them wanted a bigger shape and $28.7 \%$ of the students wanted to have a thinner shape.Conclusions:The prevalence of BSD was considerably high in our study population. Body shape misconception might lead to unnecessary weight reduction measures and students tend to follow unhealthy methods for weight reduction. Proactive preventive measures could be initiated targeting towards weight management and dietary practices of college students.

Keywords: Overweight, Body Shape Dissatisfaction, Weight Perceptions

\section{Background}

The changing dietary and life style habits made overweight and obesity to become a threat globally and the prevalence of obesity has doubled since 1980 worldwide. Overweight and obesity being the fifth leading risk factor for all deaths globally, nearly 2.8 million adults die

\footnotetext{
${ }^{1}$ Postgraduate student, Department of Community Medicine, Pondicherry Institute of Medical Sciences

${ }^{2}$ Assistant Professor, Department of Community Medicine, Pondicherry Institute of Medical Sciences

${ }^{3}$ Professor and Head, Department of Community Medicine, Pondicherry Institute of Medical Sciences (C) 2015 I V Prasad, Kanimozhy, Venkatachalam, Madhanraj, Z Singh; licensee IJIP. This is an Open Access Research distributed under the terms of the Creative Commons Attribution License (http://creativecommons.org/licenses/by/2.0), which permits unrestricted use, distribution, and reproduction in any Medium, provided the original work is properly cited.
} 
each year due to overweight or obesity. As on 2011, more than 40 million children worldwide are overweight and more than 30 million of them are habitants in developing countries (Obesity and overweight, 2014). Overweight and obesity are considered to be the major risk factors for the development of Non-Communicable diseases and the risk increases with increase in BMI (Body Mass Index)(Obesity and overweight, 2014). Thus obesity has currently evolved as an important public health problem in both developing and developed countries. This increase in the prevalence of overweight and obesity was attributed to urbanization, changing dietary habits and reduced physical activity(Miranda \& Smeeth, 2011; Popkin, 2004). Being an individual risk factor for developing Non-Communicable Diseases overweight should be prevented early. Body image perception is the feeling or thought about a person about his own body. Body image perception of an individual plays a major role in determining the diet and lifestyle modification to alter their body shape(Grogan, 2006). Often in India it is believed and commonly perceived that overweight individuals are healthy and well-nourished while thin and slim individuals are considered under nourished. Body image and Body Shape Dissatisfaction (BSD) may also influence the unhealthy eating behaviours, restricted dieting, binge eating and self-induced vomiting(Levine, 2004). Concern about body image and Body shape dissatisfaction are also correlated with low self-esteem and depression (Cafri, 2005). Nearly 50 to $80 \%$ of the children who are obese continue to be overweight or obese even in their adult hood period. Similarly eating disorders tend to appear immediately after puberty or during the late adolescent period which might continue during the adulthood also. This study aims at measuring the prevalence and pattern of Body shape Dissatisfaction among polytechnic college students in Puducherry.

\section{MATERIALS AND METHODS:}

The present study was carried out as a cross sectional study, among the polytechnic college students in Puducherry, a Union territory in South India. Two polytechnic colleges were selected among the four colleges in Pondicherry and all the available students in the colleges aged 15 to 25 years, during our visit were included in the study.The students were residents from both urban and rural regions of Puducherry. A structured and pretested questionnaire with Sociodemographic details, perception of their current weight, perceptions regarding overweight and obesity and Stunkard's visual figures scale was used.The Stunkard's scale consisted of 9 model body figure silhouettes ranging from a very thin shape to bigger shapes, for boys and girls separately(Figure 1). Students were asked to mark their current body shape and their desired body shape in the visual figures scale; when there is a difference between the current body shape and desired body shape the student is considered to be dissatisfied with his/her body shape. When the difference between current body shape and desired body shape was more than one then the student was considered to be extremely dissatisfied with his/her body shape. The study was conducted during September to November 2013. With the prevalence of Body Shape Dissatisfaction taken as 33\% from a study done in Mangalore, India(Goswamiet al., 2007) relative precision of $10 \%$ and alpha error of $5 \%$ the minimum required sample size was calculated to be 813 . However all the 1034 students from both the colleges were included 
andthree subsequent visits were made on consequent days to include maximum number of students. The benefits and implications of study were explained to all the participants and their voluntary written informed consent/assent was obtained from the participants before the interview. Students who did not consent for examination and interview were excluded from the study.

Procedure:Data collection was done by the trained interviewers, after which height and weight was measured for the students. Stadiometer was used for measuring height and standard dial type weighing machine was used to measure weight. Height was rounded off to the nearest $\mathrm{cm}$ and weight was rounded off to the nearest Kilogram. International WHO classification of BMI was used to categorise students aged above 18 years, while for adolescents age and gender specific BMI was calculated using WHO Anthroplus software and categorised accordingly. For the purpose of easy interpretation and comparison overweight and obesity as per the BMI are grouped together and represented as Overweight in our study.Statistical analysis: Chi-square test was used to test the statistical significance in difference between proportions, $\mathrm{p}$ value $<0.05$ was considered statistically significant. Data analysis was done using SPSS version 21 software.

\section{RESULTS:}

Using the Stunkard's visual figure scale the prevalence of Body Shape Dissatisfaction (BSD) in our study subjects was found to be $62.2 \%$ (95\% CI $=59.24 \%-65.16 \%)$. Of those who are dissatisfied with their body shapes, $56 \%$ of them wanted a bigger shape and $44 \%$ wanted a slimmer shape. Nearly $5.2 \%$ of the students were extremely dissatisfied with their current body shape and more proportion of males where extremely dissatisfied when compared to females. Proportion of students who wanted a thinner body shape was more in case of females while more male students wanted a bigger body shape than their current body shape. (Table 1)

The mean age of the study participants was 18.44 years. The prevalence of BSD was high among adolescent (64.8\%) when compared to adult students (58.8\%) and more adolescents wanted to have a thinner body shape when compared to adults. The prevalence of overweight or obesity was almost similar among students aged $\leq 18(13.2 \%)$ and $>18(13.3 \%)$. However underweight was slightly more among the students aged $\leq 18$ when compared to the other group of students. BSD was more prevalent among the younger students $(\leq 18)$, than the students aged above 18 years. (Table 2)

Only $45.3 \%$ of the students with normal BMI were satisfied with their current body shape, $26 \%$ of them wanted a bigger shape and $28.7 \%$ of the students wanted to have a thinner shape. Almost 42 students who were already underweight still wanted to have a much thinner body shape, who represented $10 \%$ of the underweight individuals. Similarly, $8 \%$ (11) wanted a bigger body shape even though they are already overweight or obese. $21.8 \%$ of our study participants perceived that they are overweight for their current age and height and $1 \%$ of them had no idea about it. Nearly $4.3 \%$ of the underweight individuals felt that they are overweight 
and $25.5 \%$ of the students who are overweight or obese did not feel that they are actually overweight. With regard to the current plan about weight management of the students, $20.8 \%$ of the study subjects wanted to reduce their weight and $22.5 \%$ wanted to increase their current weight. Despite being underweight $4.8 \%$ of the students still wanted to reduce their weight and 3 students who are overweight reported that they want to increase their current weight. $29 \%$ of the students wanted to maintain their current weight and body shape while $22.5 \%$ wanted to do nothing regarding their weight. Nearly one quarter of our study participants have ever attempted for weight reduction. (Table 3)

Almost 76\%(190) of the students who have ever tried for any weight modification methods were by using dietary modifications and $27.3 \%$ of them reported they also followed some sort of exercise or physical activity to reduce their weight. Two of the students reported that they have used weight control pills in order to reduce their weight. Among those who have tried to reduce their weight $55.8 \%$ of them reduced their quantity of meals and $51.8 \%$ of them skipped any of their meals so as to reduce their weight. Surprisingly $14.1 \%$ of them have been on fasting for more than 24 hours to achieve weight reduction. Nearly half (52\%) of the students checked their weight once in a period of more than 6 months. Only 29\% of the study subjects perceived their weight correctly as of their actual weight with a marginal error of $1 \mathrm{Kg}$. Maximum number of the students (61.5\%) overestimated their weight and 9.5\% underestimated their actual weight.

\section{DISCUSSION:}

In the present study the prevalence of BSD was found to be $62.2 \%$ and it was more among adolescents. The overall prevalence of overweight was found to be $13.25 \%$ and BSD was more prevalent among the overweight individuals. Studies and research regarding Body Image perception and Body Shape Dissatisfaction has gained more importance in the past decade, especially in the developed part of the world. By contrast there were only a very few studies in the developing world, including India. Body image is a multidimensional dynamic construct that involves internal biological and psychological factors as well as external cultural and social determinants (Geller et al., 2000).Several scales has been used for measuring BSD and Body image perception among different studies, hence the prevalence of BSD varied a lot between the studies and it was not comparable with our study results. To our knowledge from literature search there were no studies in India with Stunkard's scale for measuring Body Shape Dissatisfaction. Also very few studies were conducted India with respect to Body Image/Shape Dissatisfaction or perception. Most studies were among females and of small sample size.

Racial or ethnic differences in weight perception have been reported, in which Caucasians were found to be more likely to perceive themselves as overweight than African-Americans (Martin et al., 2010; Wang et al., 2009). A study done in Uttar Pradesh among adolescent girls showed $26.6 \%$ of them were dissatisfied with their body image and it was more among urban girls in comparison to girls from rural areas (Dixit et al., 2011). In a study by Swaminathan et al done in 
Karnataka, South India among school children reported that 73\% of overweight, 35\% of normal weight and $22 \%$ of under-weight children attempted to reduce weight which was similar to our study results (71.5\%, 23.5\% and 9.1\%). Perception of weight status was associated with weight loss attempts (Swaminathanet al., 2013). In Delhi study(Stigler et al., 2011), nearly 50\% of overweight/obese youth had body dissatisfaction, while one-quarter of the non-overweight youth felt the same; among overweight/obese youth, girls were more likely than boys to perceive themselves as overweight $(\mathrm{p}=0.047)$ and to have low body satisfaction $(\mathrm{p}=0.052)$.

The prevalence of overweight and obesity among female medical college students of age 18 to 23 at Mangalore, South India was 11\% and 33\% were unsatisfied with their current body shape. $20 \%$ of the students attempted to reduce weight and $28.6 \%$ skipped their meals to reduce weight (Priya et al., 2010). Most of the above study results were similar to our study results except for prevalence of Body image perception, since different scales were used. (Goswami et al., 2010) study on Body Image satisfaction among female college students which reported that $13.54 \%$ were dissatisfied with their body shape. However the above study also used a different scale to measure body shape dissatisfaction. According to the results of the study $11.54 \%$ of the girls were overweight or obese.

Among the studies conducted in different parts of the world, using various scales and different methodology the level of body image or shape dissatisfaction were 73.3\% (USA)(Kelly et al., 2005), 69\% (Europe)(McElhone et al., 1999), 56\% (Norway) (Meland et al., 2007), 50\% (Taiwan) (Wong et al., 1999) and 33\% (China) (Luo, Parish, \& Laumann, 2005).A study conducted to assess the relationship between body mass index and self-perception of body image by (Kakeshita \& de Sousa Almeida, 2006) showed that both men and women had a distorted self-perception of body image, underestimating or overestimating it which was identical to our study results.

In Karnataka study(Swaminathan, Selvam, Pauline, \& Vaz, 2013) it was also reported that $46 \%$ of the students indicated exercise as their preferred choice of weight reduction while in our study $27 \%$ of the students reported that they preferred exercise. (Sinhababu, 2007) conducted a study among the nursing students in West Bengal, India the results of which showed that the prevalence of faulty weight perception was $38.6 \%$ and was found to be weighted towards feeling higher weight. Similar misperceptions were also observed in our study results. The possible limitations for our study might be that it was done among polytechnic college students who may not represent general population.

\section{CONCLUSION:}

Body Shape Dissatisfaction was more prevalent among the adolescent and adult polytechnic college students in our study area. Body shape misconception might lead to unnecessary weight reduction measures and students tend to follow unhealthy methods for 
weight reduction. Proactive preventive measures could be initiated targeting towards weight management and dietary practices for adolescent college students.

\section{REFERENCES:}

Cafri, G., Thompson, J. K., Riciardelli, L. A., McCabe, M. P., Smolak, L.,\&Yeselis, C. (2005). Pursuit of the muscular ideal: Physical and psychological consequences and putative risk factors. Clinical Psychology Review, 25, 215-239.

Dixit, S., Agarwal, G., Singh, J., Kant, S., \& Singh, N. (2011). A study on consciousness of adolescent girls about their body image. Indian J Community Med, 36(3), 197-202. doi: 10.4103/0970-0218.86520

Geller, J., Srikameswaran, S., Cockell, S. J., \&Zaitsoff, S. L. (2000). Assessment of shape- and weight-based self-esteem in adolescents. Int J Eat Disord, 28(3), 339-345.

Goswami, S., Sachdeva, S., \&Sachdeva, R. (2012). Body image satisfaction among female college students. Ind Psychiatry J, 21(2), 168-172. doi: 10.4103/0972-6748.119653

Grogan, S. (2006). Body Image and Health : Contemporary Perspectives. J Health Psychol, 11, 523-530.

Kakeshita, I. S., \& de Sousa Almeida, S. (2006). [Relationship between body mass index and selfperception among university students]. Rev SaudePublica, 40(3), 497-504. doi: /S003489102006000300019

Kelly, A. M., Wall, M., Eisenberg, M. E., Story, M., \&Neumark-Sztainer, D. (2005). Adolescent girls with high body satisfaction: who are they and what can they teach us? $J$ Adolesc Health, 37(5), 391-396. doi: 10.1016/j.jadohealth.2004.08.008

Levine, M. P., \&Piran, N. (2004). The role of body image in the prevention of eating disorders. An International Journal of Research, 1(1), 57-70.

Luo, Y., Parish, W. L., \&Laumann, E. O. (2005). A population-based study of body image concerns among urban Chinese adults. Body Image, 2(4), 333-345. doi: 10.1016/j.bodyim.2005.09.003

Martin, M. A., May, A. L., \& Frisco, M. L. (2010). Equal weights but different weight perceptions among US adolescents. J Health Psychol, 15(4), 493-504. doi: $10.1177 / 1359105309355334$

McElhone, S., Kearney, J. M., Giachetti, I., Zunft, H. J., \& Martinez, J. A. (1999). Body image perception in relation to recent weight changes and strategies for weight loss in a nationally representative sample in the European Union. Public Health Nutr, 2(1A), 143-151.

Meland, E., Haugland, S., \&Breidablik, H. J. (2007). Body image and perceived health in adolescence. Health Educ Res, 22(3), 342-350. doi: 10.1093/her/cyl085

Miranda JJ, G. R., Smeeth L. (2011). Differences in cardiovascular risk factors in rural, urban and rural-to-urban migrants in Peru. Heart, 97, 787-796.

Obesity and Overweight. (2014). Available from:

http://www.who.int/mediacentre/factsheets/fs311/en/. 
Popkin BM, G.-L. P. (2004). The nutrition transition: worldwide obesity dynamics and their determinants. International Journal of Obesity, 28, S2-S9.

Priya, D., Prasanna, K. S., Sucharitha, S., \&Vaz, N. C. (2010). Body Image Perception and Attempts to Change Weight among Female Medical Students at Mangalore. Indian J Community Med, 35(2), 316-320. doi: 10.4103/0970-0218.66886

Sinhababu, A. (2007). A study on weight status and weight perception of GNM students of a nursing training centre, Bankura, West Bengal. J Indian Med Assoc, 105(2), 85-87.

Stigler, M. H., Arora, M., Dhavan, P., Shrivastav, R., Reddy, K. S., \& Perry, C. L. (2011). Weight-related concerns and weight-control behaviors among overweight adolescents in Delhi, India: a cross-sectional study. Int J BehavNutrPhys Act, 8, 9. doi: 10.1186/14795868-8-9

Swaminathan, S., Selvam, S., Pauline, M., \&Vaz, M. (2013). Associations between body weight perception and weight control behaviour in South Indian children: a cross-sectional study. BMJ Open, 3(3). doi: 10.1136/bmjopen-2012-002239

Wang, Y., Liang, H., \& Chen, X. (2009). Measured body mass index, body weight perception, dissatisfaction and control practices in urban, low-income African American adolescents. BMC Public Health, 9, 183. doi: 10.1186/1471-2458-9-183

Wong, Y., \& Huang, Y. C. (1999). Obesity concerns, weight satisfaction and characteristics of female dieters: a study on female Taiwanese college students. J Am CollNutr, 18(2), 194200.

Figure 1:Stunkard's Visual Figures Scale
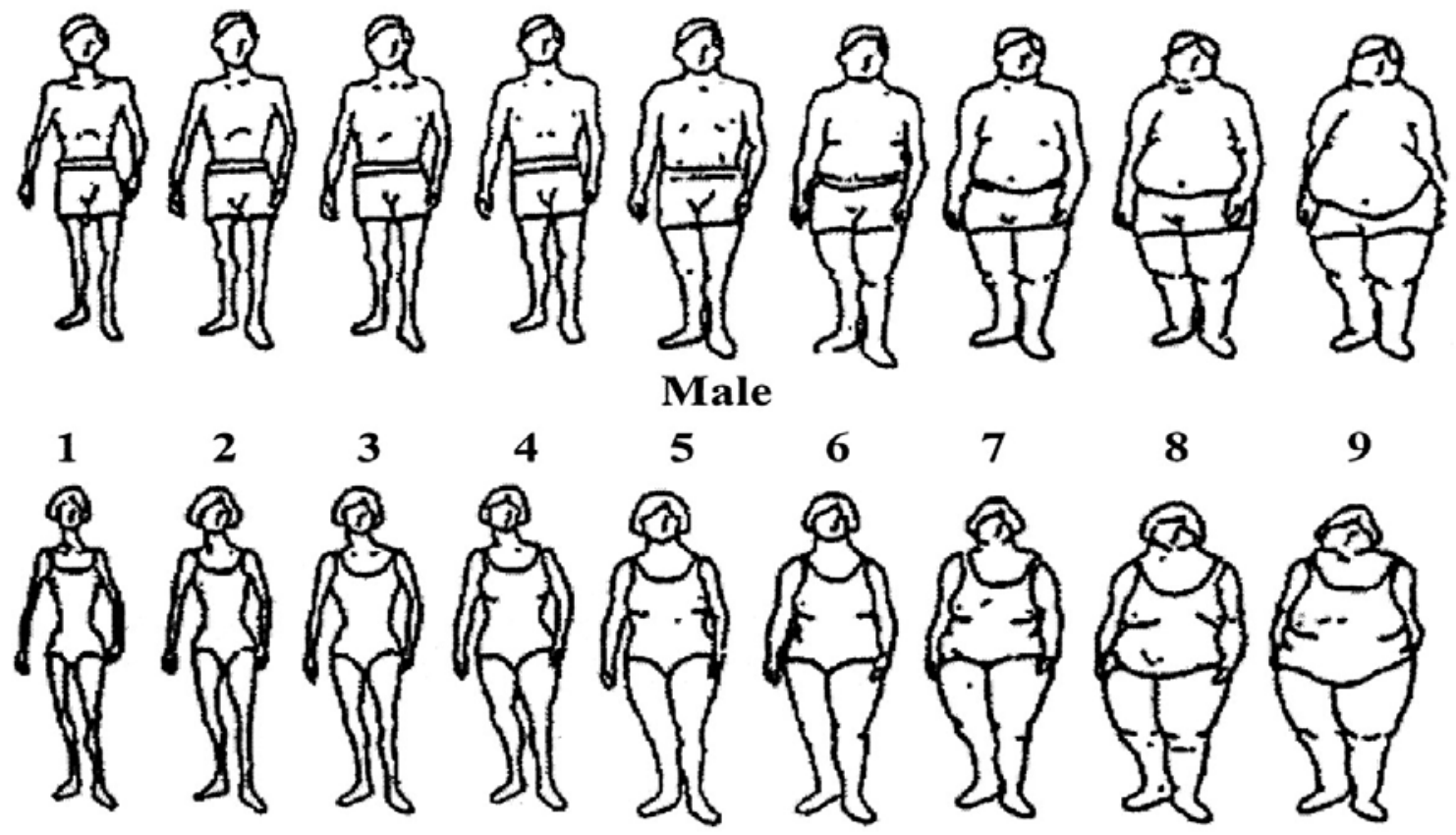

9

Female 
Body Shape Dissatisfaction and Overweight Noesis among Polytechnic College students in Puducherrya Cross Sectional Study

\begin{tabular}{|c|c|c|c|c|c|}
\hline & & & & & \\
\hline Body Shape & ssatisfaction & $\begin{array}{c}\text { Male } \\
\text { N (\%) }\end{array}$ & $\begin{array}{c}\text { Female } \\
\text { N (\%) }\end{array}$ & $\begin{array}{l}\text { Total } \\
\text { N (\%) }\end{array}$ & $\mathrm{p}$ value \\
\hline & Bigger & $248(67.2)$ & $110(40.1)$ & $358(55.7)$ & \\
\hline & Thinner & 121(32.8) & $164(59.9)$ & $285(44.3)$ & \\
\hline Satisfied & & $212(36.5)$ & $179(39.5)$ & 391(37.8) & \\
\hline Dissatisfied & & 331(57) & $258(57)$ & 589(57) & 0.081 \\
\hline Extremely d & atisfied & $38(6.5)$ & $16(3.5)$ & $54(5.2)$ & \\
\hline Total & & 581(100) & $453(100)$ & 1034(100) & \\
\hline
\end{tabular}

Table 2: Association between Age and BSD \& Overweight

\begin{tabular}{|c|c|c|c|}
\hline Age (in years) & \begin{tabular}{|l}
18 or less \\
$\mathrm{N}(\%)$
\end{tabular} & $\begin{array}{l}\text { Above } 18 \\
\mathrm{~N}(\%)\end{array}$ & $p$ value \\
\hline \multicolumn{4}{|l|}{ BSD } \\
\hline No BSD & 205(35.2) & $186(41.2)$ & \multirow{3}{*}{0.003} \\
\hline Wanted a Bigger Shape & 193(33.1) & $165(36.6)$ & \\
\hline Wanted a Thinner Shape & 185(31.7) & $100(22.2)$ & \\
\hline \multicolumn{4}{|l|}{ BMI } \\
\hline Underweight & 264(45.3) & $152(33.7)$ & \multirow{4}{*}{0.001} \\
\hline Normal & $242(41.5)$ & $239(53)$ & \\
\hline Overweight & $77(13.2)$ & $60(13.3)$ & \\
\hline Total & $583(100)$ & $451(100)$ & \\
\hline
\end{tabular}


Body Shape Dissatisfaction and Overweight Noesis among Polytechnic College students in Puducherrya Cross Sectional Study

\begin{tabular}{|c|c|c|c|c|c|c|}
\hline \multicolumn{2}{|c|}{ Current BMI } & \multirow{2}{*}{$\begin{array}{l}\text { Underweight } \\
\text { N (\%) } \\
152(36.5)\end{array}$} & \multirow{2}{*}{$\begin{array}{l}\text { Normal } \\
\text { N (\%) } \\
218(45.3)\end{array}$} & \multirow{2}{*}{$\begin{array}{l}\text { Overweight } \\
\text { N (\%) } \\
21(15.3)\end{array}$} & \multirow{2}{*}{$\begin{array}{l}\text { Total } \\
\text { N (\%) }\end{array}$} & \multirow[t]{2}{*}{$\mathrm{p}$ value } \\
\hline \multirow{3}{*}{$\begin{array}{l}\text { Pattern of } \\
\text { BSD }\end{array}$} & No BSD & & & & & \\
\hline & $\begin{array}{l}\text { Wanted a } \\
\text { Bigger } \\
\text { Shape }\end{array}$ & $222(53.4)$ & $125(26)$ & $11(8)$ & 358(34.6) & \multirow[t]{2}{*}{0.001} \\
\hline & $\begin{array}{l}\text { Wanted } \\
\text { Thinner } \\
\text { shape }\end{array}$ & $42(10.1)$ & 138(28.7) & $105(76.7)$ & $285(27.6)$ & \\
\hline \multirow{3}{*}{$\begin{array}{l}\text { Perceived } \\
\text { overweight }\end{array}$} & Yes & $18(4.3)$ & 106(22) & 101(73.8) & $225(21.8)$ & \multirow{3}{*}{0.001} \\
\hline & No & 395(95) & $369(76.7)$ & $35(25.5)$ & 799(77.2) & \\
\hline & No Idea & $3(0.7)$ & $6(1.3)$ & $1(0.7)$ & $10(1)$ & \\
\hline \multirow{4}{*}{$\begin{array}{l}\text { Current } \\
\text { following } \\
\text { measure to }\end{array}$} & $\begin{array}{l}\text { Reduce } \\
\text { weight }\end{array}$ & $20(4.8)$ & 95(19.8) & $100(73)$ & $215(20.8)$ & \multirow{4}{*}{0.001} \\
\hline & $\begin{array}{l}\text { Maintain } \\
\text { weight }\end{array}$ & $110(26.4)$ & 157(32.6) & $12(8.7)$ & $279(29)$ & \\
\hline & $\begin{array}{l}\text { Increase } \\
\text { weight }\end{array}$ & 195(46.9) & 109(22.7) & $3(2.2)$ & $307(29.7)$ & \\
\hline & $\begin{array}{l}\text { None } \\
\text { followed }\end{array}$ & $91(21.9)$ & $120(24.9)$ & $22(16.1)$ & 233(22.5) & \\
\hline \multirow{2}{*}{$\begin{array}{l}\text { Ever tried } \\
\text { to reduce } \\
\text { weight }\end{array}$} & Yes & 38(9.1) & $113(23.5)$ & $98(71.5)$ & $249(24.1)$ & \multirow{2}{*}{0.001} \\
\hline & No & 378(90.9) & $368(76.5)$ & $39(28.5)$ & 785(75.9) & \\
\hline Total & & 416(100) & 481(100) & 137(100) & 1034(100) & \\
\hline
\end{tabular}

